\title{
TIC E LITERATURA INFANTIL: DESAFIOS DA PRÁTICA PEDAGÓGICA NA ERA DIGITAL*
}

\section{ICT AND CHILDREN'S LITERATURE: CHALLENGES OF PEDAGOGICAL PRACTICE IN THE DIGITAL AGE}

\author{
Juliana Prestes de Oliveira \\ Universidade Federal de Santa Maria, Brasil \\ jprestesdeoliveira@gmail.com
}

\begin{abstract}
RESUMO: Este trabalho busca refletir em que medida há desafios na implementação das Tecnologias da Informação e Comunicação (TIC) na organização pedagógica de professores de Literatura, mais especificamente de doutorandas em Letras - Área Estudos Literários. Além disso, procura-se pensar sobre a formação/capacitação docente, principalmente no que diz respeito ao ensino de Literatura Infantil. Ao atentar-se para tais ideias, foi proposto o auxílio de duas pós-graduandas, que estavam passando pela experiência de Docência orientada, na disciplina de Literatura Infantil, do Curso de Pedagogia da UFSM, na utilização de TIC para o ensino-aprendizado de Literatura. Nessa ocasião, foi avaliado se os recursos auxiliaram-nas a atingir o objetivo, a finalidade pretendida e se despertaram nos alunos o interesse pelo conteúdo, contribuindo para o aprendizado. A partir da análise dos relatórios, percebeu-se que aprender como aplicar as TIC em sala de aula e usá-las é importante.
\end{abstract}

PALAVRAS-CHAVE: TIC; literatura Infantil; prática pedagógica; narratologia.

ABSTRACT: This paper reflects upon the challenges while implementing information and communication technologies (ICT) in the pedagogical organization of literature teachers, in particular those of language and literature PhD students. Furthermore, we seek to reflect upon teacher's training, mainly concerning children's literature teaching. By taking such aspects into consideration, it has been proposed the support of two post-graduate students going through an oriented teaching experience (Docência Orientada) in a Children's Literature course, in the context of the Federal University of Santa Maria (UFSM) pedagogy undergraduate degree, while using ICT for literature teaching and learning. In this context, it has been checked whether the resources they used helped achieve their goals and whether they aroused student's interest in the content, thus fostering learning. From the analysis of the reports, it became clear that learning how to apply and use ICT in the classroom is important.

KEYWORDS: ICT; children's literature; pedagogical practice; narratology.

* Este artigo é um recorte do Trabalho de Conclusão de Curso (TCC) apresentado como requisito para finalização do Curso de Especialização em TIC aplicadas à educação, modalidade EaD, da UFSM, sob orientação da Prof. Dr. Cândida Martins Pinto. 


\section{Introdução}

No sistema tradicional de ensino, muitas vezes observam-se alunos desmotivados, sem interesse pelo que está sendo abordado em sala de aula. Essa situação pode então resultar em baixo desempenho, falta de atenção e de compreensão no plano de ensino da disciplina e na didática do professor, e dificuldades em ver os benefícios de frequentar a escola. A justificativa para esses resultados pode residir no fato de esses alunos estarem acostumados, no seu dia a dia, a acessarem informações diversas por meio de recursos tecnológicos, tais como: internet, redes sociais, sites, smartphones, tablets, entre outros. $\mathrm{Na}$ maioria das vezes, esses recursos são mais interessantes, funcionais e eficazes do que ficar sentado por horas ouvindo um professor falar.

O comportamento dos estudantes em relação ao uso de tecnologias pode contribuir para que o modo de construir a Educação seja revisto. Ao observá-los com atenção, os educadores e pesquisadores atentaram-se ao potencial desses jovens e das tecnologias existentes. Dessa forma, construir uma prática educacional baseada em paradigmas retrógrados é insuficiente para atender esses alunos e para se alcançar o aprendizado almejado.

A tecnologia, em geral, pode auxiliar a educação em diversos aspectos, desde que haja sua disponibilização nas escolas, infraestrutura adequada, manutenção constante e engajamento dos professores em utilizá-las em suas práticas pedagógicas. Um desses aspectos é a relação que se estabelece entre professor e alunos, pois pode-se inserir o estudante na elaboração e condução da aula. Destarte, o estudante torna-se agente ativo da construção de seu aprendizado e o docente passa a ser um mediador, auxiliando o discente no uso consciente dos recursos tecnológicos. As Tecnologias da Informação e Comunicação (TIC) podem, então, contribuir para o desenvolvimento intelectual tanto do aluno quanto do professor. Dessa maneira, entendo que o professor se transforma em um facilitador do processo de ensino-aprendizagem. Para isso, ele precisa utilizar abordagens que considerem as características de cada turma e o que se deseja aprender.

Entretanto, quando penso em TIC e educação, logo reflito sobre as dificuldades de sua incorporação às práticas docentes. A partir disso, observo que um dos pontos principais para que as TIC sejam incorporadas à prática docente é o professor, que, em vez de tentar evitar as tecnologias digitais e virtuais, tratando-as como uma "tendência de época", precisa aceitá-las em seu papel de participante na constituição dessa nova realidade global. Observem-se, por exemplo, as mudanças significativas no mercado de trabalho, que passa a exigir, cada vez mais, profissionais capacitados a trabalhar com processamento de dados e conteúdos afins.

No decorrer nos dias, tenho percebido, guiada por estudos sobre recurso tecnológicos, o crescimento incessante das TIC e o uso das mais diversas formas, tais como redes sociais, aplicativos, websites, softwares e programas. Essa presença veemente mostra que tais ferramentas têm papel fundamental na formação intelectual do ser humano e nas atividades cotidianas, descartando a ideia de que elas não serão mais utilizadas com o passar do tempo. Então, por que não utilizar as TIC na sala de aula para auxiliar no ensino-aprendizado das disciplinas curriculares? Por que nós, docentes, não buscamos desenvolver, além das habilidades e competências exigidas pela disciplina, aquelas relacionadas aos recursos tecnológicos digitais? 
Levando em consideração essas indagações, a minha experiência docente e pesquisas ligadas à Literatura, iniciei a reflexão acerca dos desafios para a implementação das TIC no ensino da Literatura Infantil, pensando em uma forma de incentivar os docentes a usar as TIC, interagindo com os alunos, promovendo a leitura e o pensamento crítico deles. Nesse contexto, buscando-se leituras que abordassem o ensino de Literatura e TIC, surgiram os seguintes questionamentos: como o professor de literatura pode modificar sua prática pedagógica e utilizar os recursos tecnológicos para o ensino-aprendizado de Literatura? Quais desafios o docente enfrentará para colocar em prática as TIC em sala de aula? As ferramentas disponíveis na web realmente auxiliam no aprendizado do estudante de Literatura? As ferramentas Prezi, vídeo, animação e Google Drive ajudam os alunos a compreenderem e absorverem o conteúdo abordado, despertando-Ihes o interesse em conhecer mais as obras literárias estudadas e a ler mais? Como as tecnologias podem contribuir ou prejudicar o processo de ensinoaprendizagem?

Com base nesses questionamentos, busquei refletir, neste trabalho, em que medida há desafios na implementação das TIC na organização pedagógica de professores de Literatura, bem como pensar sobre a formação/capacitação docente, principalmente no que diz respeito ao ensino de Literatura Infantil. Para isso, propus-me a auxiliar duas pós-graduandas, que estavam passando pela experiência de Docência orientada $^{1}$, na disciplina de Literatura Infantil, do Curso de Pedagogia da UFSM, na utilização de TIC (como Prezi, vídeo, animação, e Google Drive) para o ensinoaprendizado de Literatura. Posteriormente, intentei refletir sobre as experiências de utilizar as TIC na prática docente. Nessa pesquisa, o suporte metodológico adveio da abordagem qualitativa descritiva, caracterizando-se como estudo de caso e pesquisa-ação, visto que é uma proposta de auxílio às pós-graduandas. O desenvolvimento dessa investigação deu-se no $1^{\circ}$ semestre de 2018, cujo foco foi a elaboração do planejamento das aulas de Literatura Infantil para uma turma do Curso de Pedagogia Diurno da UFSM, com a inserção de TIC.

A perspectiva supramencionada é relevante, pois tentar manter o modo de ensinar como era no século passado pode não ser eficaz. É preciso levar para a sala de aula as tecnologias que fazem parte do cotidiano dos alunos, atrelando-as ao conteúdo do currículo escolar. O professor precisa refletir sobre quais tecnologias poderá utilizar em suas aulas, avaliar se elas o auxiliarão a atingir seu objetivo, a finalidade pretendida, e se despertará nos alunos o interesse pelo conteúdo, contribuindo assim para o aprendizado além de atentar se à possibilidade de as tecnologias contribuírem ou não para tornar as obras literárias do currículo mais interessantes.

\section{TIC e Literatura}

Utilizar as TIC, para a abordagem da Literatura em sala de aula, enquanto disciplina, é algo que pode melhorar o ensino-aprendizado. O resultado dessa

1 Docência orientada é uma disciplina da Pós-Graduação em Letras, da UFSM, pela qual os pósgraduandos devem vivenciar a docência na prática. Para isso, os discentes devem fazer estágio de observação e posterior regência em uma turma e disciplina da graduação em que seu orientador é docente. 
incorporação pode ser uma sala de aula mais interativa, onde há a coletividade, a alteridade e a interdisciplinaridade, bem como a promoção e a aproximação de diferentes áreas do conhecimento através da navegação por páginas na internet, sites, materiais online e relação com conteúdo de outras disciplinas. Dessa forma, pode-se encontrar e instigar, por exemplo, a relação entre Literatura, Artes, Filosofia, Psicologia e História, quando pesquisarmos determinado autor ou obra. A partir de um acesso a uma página, na qual há textos com links que levam a outros pontos relacionados à temática e que, por sua vez, levam ainda às demais produções e costumes de época, é possível ampliar a compreensão de determinado assunto. Assim,

[...] a informática transforma o conhecimento em algo não material, variável, fluido e indefinido, por meio dos suportes digitalizados, trazendo consigo processos provocadores de rupturas: a interatividade, a manipulação de dados, a correlação dos conhecimentos entre si por meio de links e nós de redes hipertextuais, a plurivocidade, o pagamento das fronteiras rígidas entre texto-margens e autoresleitores, a relativização da objetividade do conhecimento e da busca de verdades definidas (RAMAL, 2002, p. 14, grifo do autor).

Ao refletir sobre o acima mencionado e se avalio a sociedade atual e sua relação com a tecnologia e o modo como os recursos digitais diariamente, percebo que a escola é menos livre que a sociedade, devido à falta de interdisciplinaridade e à conexão ao extraclasse, no decorrer das aulas. Essa cisma emerge principalmente do que é estudado em sala de aula, onde se trabalham conteúdos inseridos em um currículo fechado, prédefinido, aquém às particularidades de cada região do país, bem como do modo como esses conteúdos são abordados, submetendo a Literatura a essa realidade. Mesmo que, com o passar dos anos e avanços sobre metodologias de ensino, pouco tenha sido alterado no método de ensino, "[...] não significa que as teorias e [as] práticas sejam imutáveis. Ao contrário: a escola, assim como todo elemento de cultura, é histórica, e precisa mudar" (REZENDE, 2013, p. 109). O modo como o conteúdo será trabalhado pode ser modificado, buscando-se atender às necessidades e demandas do público que frequenta a sala de aula. Sendo assim, as TIC podem ser incorporadas no processo de ensino da Literatura. Para tanto, muitas vezes.

[...] é preciso ousar, vencer desafios, articular saberes, tecer continuamente a rede, criando e desfrutando novos nós conceituais que se inter-relacionam com a integração de diferentes tecnologias, com a linguagem hipermídia, as teorias educacionais, aprendizagem do aluno, a prática do educador e a construção da mudança em sua prática, na escola e na sociedade. Essa mudança torna-se possível ao propiciar ao educador o domínio da TIC e o uso desta para inserir-se no contexto e no mundo, representar, interagir, refletir, compreender e atuar na melhoria de processos e produções, transformando-se e transformando-os (ALMEIDA, 2005, p. 73).

Fica evidente que é possível atrelar as práticas pedagógicas e experiências ao uso das TIC. Não há necessidade de abandonar os livros literários, mas usar as TIC como aliadas para levar o aluno a lê-los e, consequentemente, despertar o interesse dos estudantes pelo conteúdo abordado na disciplina de Literatura. Segundo Rezende, uma das maiores dificuldades do ensino de literatura "[...] não se encontra na resistência dos alunos à leitura, mas na falta de espaço-tempo na escola para esse conteúdo que insere 
fruição, reflexão e elaboração, ou seja, uma perspectiva de formação não prevista no currículo, não cabível no ritmo da cultura escolar" (REZENDE, 2013, p. 111). Nesse sentido, onde se observa a falta de bibliotecas ou de bibliotecas equipadas com os exemplares que estão no currículo escolar, as TIC servem para auxiliar os docentes e discentes no acesso aos livros e materiais críticos relacionados.

Todavia, há inúmeros professores que não querem utilizar os livros e materiais digitais, porque acreditam que eles não substituem o prazer em manusear, segurar e ler um livro impresso, e que, caso se abra espaço para o livro digital e para a internet, o professor não será mais necessário. O que é relevante compreender, diante de certas realidades escolares, onde, por exemplo, observa-se a ausência de exemplares e livros suficientes para todos os alunos, é que "[o] material eletrônico não substitui completamente o material impresso, e o professor continua a ser indispensável" (BELLEI, 2012, p. 143). Desse modo, o material eletrônico serve para auxiliar os alunos e, principal e essencialmente, os professores, e propiciar-Ihes novas possibilidades.

Os professores não serão substituídos, uma vez que eles são importantes para a mediação entre os alunos e os recursos digitais. São os docentes quem auxiliarão os alunos a utilizarem os recursos da melhor maneira, tanto em sala de aula como em casa, pois "[...] entende-se que os professores são sujeitos dos saberes e mediadores de toda ação pedagógica que ocorre no interior da escola" (COPPOLA; RAMOS, 2009, p. 3). São eles que indicarão aos alunos como e onde pesquisar, quais os websites mais confiáveis e os meios mais ágeis e frutíferos, como baixar arquivos de maneira segura e livros completos. Sendo assim, há a necessidade de que os professores se apropriem "[...] das novas tecnologias, não apenas para motivar os alunos, mas para compreender o processo ativo e dinâmico que ocorre nessa interação entre homem e a máquina" (COPPOLA; RAMOS, 2009, p. 3).

Uma das formas de os professores manterem-se atualizados em relação ao ambiente escolar e às inovações e pesquisas sobre práticas docentes é por meio dos estágios e da docência orientada e, principalmente, da formação continuada. A docência orientada e a formação continuada docente são importantes momentos para observar os alunos, pensar a prática docente e traçar estratégias que conectem, da melhor maneira possível, prática e teoria.

De acordo com Barreiro e Gebran (2006, p. 118), "a formação para a docência de qualidade deve se pautar na perspectiva investigativa, na qual a pesquisa, assumida como princípio científico e educativo, apresenta-se como uma proposição metodológica fundamental para o rompimento das práticas de reprodução", buscando maneiras de construir um ensino-aprendizado interativo. Porém, o professor deve ter a clareza que sua formação continuada "não se constrói por acumulação (de cursos, de conhecimentos ou de técnicas), mas sim através de um trabalho de reflexividade crítica sobre as práticas e de (re)construção permanente de uma identidade pessoal" (NÓVOA, 1995, p. 25). Assim, não basta apenas realizar vários cursos, mas pensar como o aprendido pode ser usado em sala de aula. Destarte, a prática docente se manterá sempre em atualização, buscando atender à multiplicidade da escola e às gerações de alunos que a constituem.

O constante aprendizado e aprimoramento profissional estão ligados ao trabalho diário em sala de aula, no planejamento das aulas e na busca por meios e oportunidades para melhorar a prática docente. Quando há a articulação entre as mais diversas formações do professor com as práticas de sala de aula, a chance de um ensino- 
aprendizado ineficiente e retrógrado será menor. Para Vaillant e Marcelo (2012, p. 196), não são tão proveitosas as práticas de formação "[...] que não relacionam as situações de formação com as práticas de sala de aula, as experiências mais eficazes para o desenvolvimento profissional são aquelas que estão baseadas na escola e que se inscrevem dentro das atividades cotidianas dos professores" (VAILLANT; MARCELO, 2012, p. 196). Sendo assim, propiciar aos professores a oportunidade de realizar a formação docente, seja por meio de docência orientada ou cursos de formação continuada, auxilia no melhoramento da educação e na valorização do docente.

\section{Metodologia da pesquisa}

Para o desenvolvimento desta pesquisa, optei por acompanhar a disciplina de Literatura Infantil, ministrada pelo Professor Heitor Ferreira ${ }^{2}$ e suas orientandas de Doutorado em Letras (Morgana e Mariele ${ }^{3}$ ), no Curso de Pedagogia da UFSM. Durante esse processo, procurei auxiliá-las no uso de TIC no desenvolvimento da disciplina. Dessa forma, pretendi contribuir para o aprendizado das docentes em atividade, bem como dos alunos do curso de Pedagogia ${ }^{4}$ (futuros docentes), em relação aos recursos que podem utilizar em suas práticas pedagógicas e acerca do conteúdo da disciplina. Intentei, também, apresentar a importância da formação continuada dos professores, a fim de conscientizá-las sobre a necessidade de buscarem estar mais próximas da realidade dos discentes, além de se informarem acerca dos recentes pensamentos sobre as práticas pedagógicas.

O planejamento supracitado surgiu na disciplina de Sala de aula e TIC, que cursei no $1^{\circ}$ semestre de 2018, durante o Curso de Especialização em TIC aplicadas à educação. Nessa disciplina, eu deveria criar um plano de aula ${ }^{5}$ e atuar em sala de aula, incorporando alguma TIC à metodologia de ensino. Ao ingressar nessa Especialização, como o foco se dava na temática de ensino de Literatura com uso de tecnologias, e surgiu a oportunidade de oferecer auxílio à Morgana e Mariele durante a sua Docência orientada, procurei unir os dois objetivos: TIC e ensino de Literatura e o proposto na disciplina Sala de aula e $\mathrm{TIC}^{6}$. Assim, nasceu a ideia de desenvolver a atividade como uma espécie de formação docente. Digo 'espécie de formação docente' porque a

2 Este nome é um nome fictício utilizado a fim de preservar o nome verdadeiro e imagem do professor. Heitor Ferreira é formado em Licenciatura em Letras e Doutor em Letras Literatura. Atualmente é professor do Departamento de Letras Vernáculas e do Programa de Pós-Graduação em Letras, ambos da UFSM.

3 Os nomes das doutorandas também foram substituídos por nomes fictícios, com o intuito de preserválas. Morgana possui Licenciatura em Letras Português-Inglês e mestrado em Letras Literatura. Atualmente, é doutoranda do Programa de Pós-Graduação em Letras - Estudos Literários. Mariele é graduada em Licenciatura em Filosofia e mestre em Letras - Literatura. Atualmente, é doutoranda do Programa de Pós-Graduação em Letras - Estudos Literários.

4 A turma era composta por 25 alunos, sendo a maioria do sexo feminino e com predominância de idade entre 18 e 25 anos.

5 O plano de aula pode ser acessado pelo link a seguir: https://drive.google.com/drive/folders/1yk_9p_5iQSkPfnT1WHZ4rNwAhpyuHl-y?usp=sharing

6 O plano de ensino apresentado na disciplina de Sala de aula e TIC foi construído em parceria com as doutorandas, a fim de acordarmos quais TIC seriam usadas em sala de aula. 
atividade não está no molde tradicional de curso de formação docente, em que um palestrante ministra determinado assunto, ou ensina como utilizar determinado recurso, para uma turma de docentes, gerando certificação ao final, mas sim uma reunião de grupo que procura pensar e construir junto um método de ensino, trocando conhecimentos e experiências.

Na Docência orientada, Morgana e Mariele, após fazerem a etapa de observação, iniciaram a regência. Nessa parte, elas tiveram que ministrar quatro seminários sobre os contos João e Maria, Chapeuzinho Vermelho, Rapunzel e Branca de Neve, respectivamente, um a cada semana, fazendo a abordagem da estrutura do conto e sua análise. Para isso, buscou-se utilizar alguma TIC que auxiliasse na realização do seminário. Após o término de cada apresentação e análise do conto, as doutorandas discorreram sobre um plano de aula, organizado para uma turma do Ensino Fundamental - Anos iniciais, em que o conto em questão seria trabalhado com as crianças. As TIC, portanto, deveriam ser incorporadas nesse plano. Essa atividade iniciou em 4 de abril de 2018 e terminou em 2 de maio de 2018.

Após a etapa de observação e de regência, na docência orientada, Morgana e Mariele elaboraram seus Relatórios da Docência Orientada, a fim de narrar como ocorreram as suas práticas pedagógicas e refletir sobre elas, elegendo os métodos que funcionaram e os que não deram certo. A escrita de um relatório, após a regência, muito mais que apenas um documento comprobatório da presença das alunas em sala de aula e realização da atividade, pode contribuir significativamente para o processo de formação desse profissional, pois é um instrumento mediador para a construção da reflexão crítica sobre a teoria e prática e sobre a ação profissional do docente.

Fez-se importante, então, realizar a análise do Relatório da Docência Orientada de Morgana e Mariele. Por meio dele busquei compreender como foi a experiência das doutorandas ao prepararem aulas, pensando na incorporação de TIC à prática docente; ministrarem a disciplina, utilizando o plano de aula elaborado e as TIC planejadas; e refletirem sobre esse exercício. A reflexão acerca dos desafios da utilização de TIC para o ensino e aprendizado de Literatura Infantil, a partir da análise do relatório produzido por cada uma das alunas ${ }^{7}$, será relatada na próxima seção. Para isso, utilizei o viés da narratologia, de Mike Bal (2017), atentando-me para as perspectivas das doutorandas que aparecem no texto, bem como a focalização ${ }^{8}$ da voz narrativa sobre a temática, tratando o texto do relatório como uma narrativa que traz à tona a subjetividade, a voz das autoras.

\section{Pontos de vista de Morgana e Mariele}

As doutorandas Morgana e Mariele têm interesse em aprender novas ferramentas e recursos que lhes auxiliem na docência. Elas intentam aproximar-se ao modo como os

7 O relatório de cada doutoranda pode ser acessado pelo link https://drive.google.com/drive/folders/1yk_9p_5iQSkPfnT1WHZ4rNwAhpyuHI-y?usp=sharing

8 De acordo com Reis e Lopes (1996), focalização é a representação das informações ao alcance da consciência do narrador. Focalização também pode ser compreendida pelos termos: ponto de vista, visão, restrição de campo e foco narrativo. O conceito de focalização está atrelado à quantidade de informação e à qualidade dela. Essas informações podem traduzir posicionamentos afetivos, ideológicos, éticos e morais do narrador em relação aos acontecimentos narrados. 
alunos estão construindo seu conhecimento atualmente, desejando aprender como podem usar seus conhecimentos para integrar TIC e educação, principalmente no que diz respeito ao ensino de Literatura. Ambas doutorandas, durante o desenvolvimento deste trabalho, buscaram absorver o máximo possível das indicações por mim sugeridas. Porém, sentiram-se frustradas, algumas vezes, por alguns recursos não funcionarem como o esperado, mas mesmo assim não abandonaram a ideia de usar essas ferramentas em sala de aula.

Conforme exigido pela Coordenação da Pós-Graduação em Letras da UFSM, uma das seções do Relatório da Docência orientada é a reflexão sobre a prática docente. Morgana e Mariele, em seus respectivos relatos, mantiveram o item com o nome "Considerações sobre a experiência da Docência orientada"'. Elas escreveram em terceira pessoa (conforme orientação dada acerca da escrita do documento), o que permite a utilização da teoria da narratologia, visto que há um narrador que conduz a diegese, a focalização e as perspectivas das personagens e do enredo. O texto inicia relatando, especificamente, sobre a experiência da Docência orientada. Portanto, esta seção objetiva analisar os pontos de vista de Morgana e Mariele no que concerne suas experiências, o papel das TIC e os desafios encontrados com seus usos no ensino de Literatura.

\title{
4.1 Experiências com a Docência orientada: o pensar da prática docente
}

Uma das reflexões abordadas pelas doutorandas, no relatório, foi acerca da relevância da Docência orientada para a formação docente. Segundo a focalização do narrador do documento de Morgana, a doutoranda é consciente em relação a sua própria experiência, reconhecendo a importância de vivenciar a sala de aula e sempre repensar suas práticas, revisando-as e pesquisando formas de sanar os problemas encontrados, intentando a manutenção de um ensino de qualidade:

\begin{abstract}
A experiência proporcionada pela docência orientada é pessoal e profissionalmente enriquecedora. O processo realizado ao, em um primeiro momento, observar as aulas e, depois, fazer a efetiva aplicação, possibilita que a doutoranda presencie e vivencie vários dos momentos importantes na licenciatura. Além disso, o contato com os alunos da graduação e com o professor da disciplina viabiliza uma oportunidade única, uma vez que a doutoranda é, ao mesmo tempo, estudante e docente, colocando-se no entremeio dessa experiência. Ademais, essa atividade exige que a aluna de doutorado revise, constantemente, seus conceitos e ideias sobre a profissão e sobre a área na qual pesquisa. Além de, neste caso, refletir a respeito do trabalho na área de literatura na educação infantil (MORGANA $^{10}, 2016$, [n. p.], grifos nossos).
\end{abstract}

Continuando sobre o reconhecimento, por parte de Morgana, da importância da formação continuada, o narrador tece um comentário que revela a voz implicada da autora. Com isso, acessamos o ponto de vista dela sobre o compartilhamento de conhecimentos acerca das TIC, entre ela e eu, o qual se mostrou positivo. Além disso, a

9 Apesar de os textos das doutorandas estarem fragmentados no decorrer deste trabalho, eles estão na íntegra nos relatórios disponíveis no link já mencionado.

10 O nome original da doutoranda foi modificado a fim de preservar sua imagem. Assim, a autoria do documento foi também alterada nas referências e no relatório. 
voz narrativa revelou a perspectiva da doutoranda referente à utilização do ambiente de aprendizagem virtual Moodle durante as aulas de Literatura infantil, ao indicar a sua satisfação ao percebê-lo como uma ótima ferramenta. Nesse comentário, a narradora considera o processo de diálogo entre Morgana, Mariele e eu como facilitador para o uso dos recursos escolhidos.

Incorporar o uso da TIC, segundo a voz de Mariele, proporciona "[...] tanto à docente quanto aos alunos(as) refletirem sobre a importância de nos capacitarmos diante das inovações e recursos tecnológicos disponíveis para o aprimoramento educacional" (MARIELE, 2018, [n. p.]). Destarte, tanto para Morgana quanto para Mariele o processo de formação continuada foi e é importante. O trabalho aqui desenvolvido ampliou a perspectiva de ambas as doutorandas acerca dos pontos positivos em aprender e usar as TIC na prática docente.

Para Mariele, segundo a perspectiva apresentada pelo narrador, a experiência proporcionada pela Docência orientada foi enriquecedora e oportunizou a ela "[...] colocarse no lugar de professor (a) universitário" (MARIELE, 2018, [n. p.], grifo da autora), bem como ampliar sua "[...] formação humana, uma vez que lida com a diversidade humana em sala de aula, já que se vê diante de graduandos(as) de diversas classes sociais, faixa etária, etnias e projetos existenciais diversos" (MARIELE, 2018, [n. p.]).

A focalização da voz narrativa revela o processo, desenvolvido na disciplina de Literatura Infantil, como um momento de pensar e repensar a prática docente, ressaltando-se a importância dessa disciplina para Mariele e demais pós-graduandos:

O fato de a doutoranda habitar esses dois mundos, a saber, enquanto estudante e, através da docência, enquanto docente, viabiliza uma oportunidade de reflexão única em seu processo formativo, facilitando, inclusive, que durante a elaboração das aulas, o processo de colocar-se no lugar do aluno (a) para pensar uma aula mais interativa seja mais corriqueiro, fazendo com que a reflexão sobre a sua atuação profissional futura esteja sempre presente (MARIELE, 2018, [n. p.], grifos nossos).

Mariele viu, conforme apontado pelo narrador, a docência em uma disciplina de Literatura Infantil, para alunos do curso de Pedagogia, como "[...] uma tarefa que por si só exige comprometimento ético, tendo em vista que esses professores(as) é que estarão efetivamente habitando lugares de transformação humana efetiva, como o ambiente escolar" (MARIELE, 2018, [n. p.]). Essa perspectiva vai ao encontro da discussão de Nóvoa (1995) e de Rezende (2013), que discutem sobre a necessidade da constante reflexão sobre o modo de lecionar e da escola se reinventar a fim de atender às novas demandas de seus alunos, respectivamente.

Outro ponto que observo é que, à medida que construímos as aulas juntas, pudemos trocar experiências e conhecimento que contribuíram para nossa formação docente. Poder auxiliar Morgana e Mariele a aproximarem-se das TIC foi gratificante, principalmente devido ao empenho e vontade de aprender que ambas demonstraram. Proporcionar a capacitação de professores promoveu a efetivação do aprendizado adquirido durante o Curso de especialização em TIC aplicadas à educação. A minha própria formação pode ser posta em prática e refletida, o que permitiu a retomada de conceitos e ideias discutidas ao longo do curso. 


\title{
4.2 O reconhecimento da possibilidade de integração de TIC no ensino
}

Nos relatórios, é possível perceber também a preocupação das doutorandas em, além de aprender sobre as TIC, passar para os alunos de Pedagogia (futuros professores do Ensino Fundamental) o que elas aprenderam sobre ferramentas que podem ser usadas no ensino, bem como recursos educacionais. A perspectiva de Morgana fica evidente quando o narrador menciona a utilização das TIC e os motivos que a levaram a isso, reforçando a ideia da necessidade da reflexão diante da prática escolar:

\begin{abstract}
Outro ponto a ser evidenciado é a tentativa do trabalho com tecnologias de informação aplicadas à educação com o intuito de tornar as aulas mais dinâmicas e interativas. A utilização de certos recursos foi escolhida também ao refletir a respeito das possibilidades de propostas de atividades a serem trabalhadas com os alunos do ensino básico. Sendo assim, ao expor os materiais disponíveis, a doutoranda pretendia fazê-los conhecer pelos graduandos que terão futuro contato com alunos da educação infantil, por exemplo. Nesse sentido, buscou-se melhorar não apenas a interação entre estudantes e professora (no caso a doutoranda), bem como expandir as possibilidades propiciadas por atividades mais dinâmicas que convidem as crianças a participar (MORGANA, 2018, [n. p.], grifos nossos).
\end{abstract}

No final desse excerto, o narrador cede o foco à doutoranda, a fim de evidenciar o ponto de vista dela sobre os benefícios do uso das ferramentas. Com isso, é possível perceber que, por meio do contato com as TIC, entendimento de seu funcionamento, aplicação em sala de aula e contato com os alunos, a doutoranda compreendeu como as tecnologias, quando planejadas de acordo com a realidade da escola e dos alunos, podem promover a integração e tornar as aulas mais dinâmicas, interessantes e próximas aos universos dos alunos. Ao relatar mais especificamente sobre o modo como os recursos foram usados, a focalização do narrador aponta para o reconhecimento e conscientização de que os recursos tecnológicos podem causar mudanças significativas na condução e resultado positivos em uma aula.

Ademais, no relatório de Mariele, é possível perceber, por meio da focalização do narrador, a voz implicada da doutoranda sobre as TIC. Assim como Morgana, Mariele acredita que "[...] os usos das tecnologias de informação possibilitaram que as aulas na docência fossem desenvolvidas de forma atrativa e dinâmica" (MARIELE, 2018, [n. p]).

Ao término de cada aula, Morgana e Mariele relatavam a participação dos alunos e como suas aulas haviam instigado os alunos a discutirem o conteúdo abordado. Além disso, elas reconheciam que o uso de ferramentas para apresentação de conteúdo, de forma planejada e dinâmica, fazia os alunos prestarem atenção ao que elas estavam propondo e discutindo. Essa animação auxiliava na proposição dos próximos recursos. Promover a formação continuada, assim, mostrava-se eficaz e significativo.

\subsection{Análise das TIC utilizadas: pontos positivos e desafios}

De acordo com o relatório de Morgana, as TIC "[...] serviram como ótimo suporte para as discussões individuais de cada conto" (MORGANA, 2018, [n. p.]), principalmente devido ao uso de apresentação de multimídia, pois, para Morgana, conforme aponta a informação prestada pelo narrador, a 
[...] apresentação exposta funcionava como um guia, com esquemas que impulsionavam as reflexões e propulsam de ideias no grupo da classe. Além disso, a possibilidade de exposição de imagens auxiliava muito a explanação, pois que as histórias infantis têm variadas interpretações nos mais diversos meios artísticos. A exposição com o projetor também auxiliou para o trabalho com as diferentes versões de cada conto, através da possibilidade de exibir vídeos, tais como curtas-metragens, trailers de filmes, vídeos de óperas e ballets, entre outros (MORGANA, 2018, [n. p.], grifos da autora).

A partir desse relato, percebo um saldo positivo adquirido com essa prática de formação de professores. Morgana pode constatar, na prática, como as TIC podem auxiliar no desenvolvimento das aulas e instigar os alunos a participarem ativamente do processo de ensino-aprendizagem. Torna-se evidente, portanto, que os recursos tecnológicos, se bem usados e planejados, podem contribuir para o ensino de Literatura, principalmente se o professor traçar ligações entre obras literárias e as suas transposições midiáticas.

As TIC, quando incorporadas no plano de ensino, ajudam os alunos a compreender e absorver o conteúdo abordado, despertando o interesse em conhecer mais as obras literárias estudadas e a ler mais. Ao observar as aulas das doutorandas, pensadas com o uso das TIC, percebi que os estudantes interagiam com diferentes contos de diferentes maneiras, tais como imagens, vídeos, sons. Eram apresentadas perspectivas outras de abordar a Literatura infantil, o que contribuía para que a interação acontecesse.

O Moodle foi visto como "[...] espaço a discussões extraclasses entre os alunos e os professores" (MORGANA, 2018, [n. p.]), "[...] para mediar o diálogo entre professores e alunos (as). O Moodle também serviu como ferramenta de compartilhamento das sequências didáticas elaboradas pela docente e pelos alunos(as), facilitando, desse modo, a troca de saberes e informações" (MARIELE, 2018, [n. p.]), funcionando de modo satisfatório

[...] para o compartilhamento de materiais, entre eles, por exemplo, os planos com as sequências didáticas propostas pela doutoranda (bem como pelos grupos dos alunos) para o trabalho com cada conto na educação básica. De forma que todos os alunos podem ter acesso e utilizar as sequências didáticas em sua própria prática docente (MORGANA, 2018, [n. p.]).

A voz narrativa também traz à tona informações relativas ao uso de efeitos sonoros, encontrados livres de direitos autorais: "Os efeitos eram de boa qualidade e contribuiriam significativamente para contação de história, uma vez que os alunos estariam de costas, a fim de experimentar a narração apenas em seu aspecto sonoro" (MORGANA, 2018, [n. p.]). A voz implicada da doutoranda revela como é possível atrelarse às práticas já utilizadas em sala de aula, como uma contação de histórias, recursos tecnológicos diversos, como áudio, imagens, trilha sonora. Mais do que isso, comprova-se que usar TIC em sala de aula é possível e os resultados são significativos, pois auxiliam no processo de ensino-aprendizado de Literatura, visto que há mais interatividade com os alunos, da mesma forma que os convida a participarem das aulas.

Ao final do relatório, a voz narrativa indica a perspectiva da doutoranda em relação ao uso das TIC para o ensino de Literatura Infantil. Com tal relato, entendo que Morgana 
compreendeu a importância dessas tecnologias e seus pontos positivos no processo de ensino de Literatura. Foram significativas as mudanças provocadas pelas ferramentas usadas no decorrer da docência orientada, segundo Morgana, pois auxiliaram no aprendizado dos alunos e na dinâmica da sala de aula:

[...] elas servem como auxílio ímpar nas atividades a serem desenvolvidas em sala de aula. Foram elas que possibilitaram, por exemplo, a proposta de atividades nas sequências didáticas para educação básica com o uso de som e apresentação por parte dos próprios alunos. Assim como proporcionaram, através do Moodle, um espaço de conversação e reflexão entre professores e alunos da disciplina. Desse modo, essas tecnologias podem fornecer diferentes modos de trabalho que intensifiquem e diversifiquem a interação professor-aluno, deixando-o mais dinâmica, envolvendo os alunos por meio do digital, que tanto lhes agrada (MORGANA, 2018, [n. p.], grifo da autora).

No decorrer dessa prática, alguns obstáculos surgiram, desafiando as doutorandas e as forçando a traçar estratégias a fim de superá-los. Um dos desafios foi em relação à utilização do Power Point. Segundo o narrador,

O programa funcionou como o esperado. Contudo, há que se apontar as idiossincrasias no que diz respeito à personalização. Caso as alunas quisessem optar por fontes, fundos e outros elementos mais personalizados, por segurança, era preferível que transformassem a apresentação em imagem ou em PDF, para não correr o risco de alterações inesperadas ao abrir a apresentação em outro computador. Todavia, essa alteração impede a utilização dos efeitos de transição de programa, o que pode deixar a apresentação mais monótona (MORGANA, 2018, [n. p.], grifos nossos).

Nos trechos assinalados, a focalização do narrador, ao usar conjunções adversativas, traz à tona o ponto de vista da doutoranda e a necessidade de ela apontar os problemas encontrados. É possível dizer que a narrativa é um meio de avaliar a TIC escolhida, bem como refletir sobre os desafios ocorridos e modos de resolvê-los. Há a análise dos pontos positivos e negativos, propiciando ao leitor maiores detalhes sobre a ferramenta, o modo como ela pode ser usada e a opinião de Morgana.

Ainda sobre as apresentações feitas com o uso do Power Point, o narrador revela o cuidado das doutorandas em construir apresentações dinâmicas e organizadas com imagens e textos, mas que, devido aos equipamentos malconservados,

[...] houve problemas com a exibição da apresentação, em função das cores escolhidas. Apesar das alunas atentarem sempre à disposição dos elementos na apresentação, bem como às cores utilizadas para que fornecessem contraste suficiente, isso aconteceu porque a lente do projetor multimídia estava estragada, o que impossibilitava a demonstração das cores como realmente eram. Isso prejudicou também a demonstração de vídeos, gravuras, pinturas, entre outros (MORGANA, 2018, [n. p.]).

Conforme discutido na seção 2 deste trabalho, é necessário que o ambiente escolar forneça infraestrutura, equipamentos adequados e com boas condições de uso e, se possível, internet. Assim, o professor terá maior facilidade em usar as TIC em sala de aula. 
O uso do Prezi também propiciou algumas problemáticas, como observado em ambos os relatórios. De acordo com o narrador "[...] o Prezi tem o empecilho de poder ser utilizado livremente apenas para aqueles que pagam uma taxa, porém, utilizando-o online, pode-se fazer uma apresentação e exibi-la, com a condição de que se tenha acesso à internet" (MORGANA, 2018, [n. p.], grifo da autora). No relatório de Mariele, essa ferramenta também é citada como um dos desafios enfrentados, como pode ser atestado na declaração que segue: "Com relação às dificuldades encontradas na utilização dos recursos tecnológicos, destaco o uso do Prezi, por ter o empecilho de ser utilizado livremente apenas por aqueles que pagam uma taxa" (MARIELE, 2018, [n. p.], grifo nosso). Ao ser utilizada a palavra destaco, o narrador passa o foco para Mariele, possibilitando que sua voz tenha espaço e relate suas impressões. Dessa forma, é possível afirmar que tanto Morgana quanto Mariele sentiram-se frustradas por não conseguirem utilizar o Prezi como planejado.

No relatório de Morgana, ao mesmo tempo em que a voz narrativa mostra a dificuldade vivenciada pela doutoranda, ela expõe o meio encontrado pelas estudantes de doutorado para contornar a situação e a preocupação de Morgana como funcionamento dos recursos. Esse fato fica mais claro quando o narrador informa a alternativa dada por mim ("aluna da especialização") às doutorandas, diante da impossibilidade de baixar o arquivo da apresentação e imprevisibilidade do funcionamento eficaz da internet da Universidade:

[...] fazer a captura de tela enquanto passava a apresentação com as transições dinâmicas, com a utilização do programa aTubeCatcher. Desse modo, no dia da aula, a doutoranda levou consigo o link da apresentação (a ser utilizado com conexão de internet) e o vídeo da captura de tela. [...] Entretanto, a situação acabou designando um tempo extra considerável de trabalho (MORGANA, 2018, [n. p.], grifos da autora).

Nesse excerto, também é possível verificar a voz implicada de Morgana sobre os desafios do uso das TIC no planejamento pedagógico. Para ela, os imprevistos com os recursos e a necessidade de ter sempre uma segunda opção, uma vez que as ferramentas podem não funcionar durante a aula, demanda mais trabalho na preparação de como ministrar o conteúdo. Esse desafio, muitas vezes, desmotiva os professores, principalmente se tiverem muitas turmas em diferentes localidades, podendo resultar no abandono do uso das TIC.

O sentimento e reflexão, acerca da dedicação de tempo e empenho na preparação de aulas que incluem TIC, também podem ser percebidos por meio da voz narrativa do relatório de Mariele: "[...] o preparo para apresentação acabou resultando em um trabalho além do previsto para elaboração e planejamento, o que corroborou na decisão das alunas permanecerem com o auxílio do Power Point, que se mostrou uma ferramenta mais segura" (MARIELE, 2018, [n. p.], grifo da autora). Nesse excerto, a focalização do narrador traz à tona a importância de pensar o planejamento didático e deixar de usar aquilo que não dá certo. O refletir sobre a prática pedagógica e as TIC adequadas para cada ambiente escolar foi percebido pelas doutorandas, sendo um saldo positivo neste processo.

A focalização do narrador sinaliza que, mesmo havendo a preparação e atenção com o funcionamento dos recursos, podem surgir empecilhos no decorrer da aula. No 
trecho a seguir, a perspectiva de Morgana aparece por meio da voz narrativa que narra o ocorrido durante o uso de efeitos sonoros para a contação de um dos contos: "[...] apesar de testadas com antecedência, na ocasião da aula, as caixinhas de som não funcionaram devidamente, prejudicando toda a atividade" (MORGANA, 2018, [n. p.]).

Conforme mencionado na metodologia, as doutorandas pretendiam usar alguma ferramenta para criação de animação, "[n]o entanto, após iniciar as tentativas, as alunas descobriram que o vídeo, na versão livre das ferramentas disponíveis, poderia ter poucos minutos, o que impossibilitou a sua utilização na proposta pensada" (MORGANA, 2018, [n. p.]). A focalização da voz narrativa revela que, apesar da persistência das doutorandas em incorporar TIC diversas na prática docente, às vezes o recurso escolhido não era adequado à proposta. Quando isso ocorria, o uso da ferramenta era descartado e um novo modo de contar o conto era elaborado, alterando-se o plano de aula.

Tais desafios mostram a necessidade de acompanhar as mudanças e atualizações pelas quais passam as TIC disponíveis online. Isso exige do professor atenção e constante reinvenção de suas práticas pedagógicas. Elaborar um plano de aula e tentar usá-lo com diferentes turmas e de um ano para outro, ou insistir em não modificar a prática pensada, pode não ser eficaz e atrapalhar o ensino-aprendizado. A formação continuada permitiu que as doutorandas adquirissem esse entendimento e que eu testasse os conhecimentos adquiridos no decorrer do curso de especialização.

Para Morgana, de acordo com a voz narrativa, há alguns pontos negativos, como a grande demanda de tempo em preparar aula e materiais didáticos que envolvam TIC. Apesar disso, ela reconhece que isso faz parte do aprendizado do professor na inserção no mundo das tecnologias. Em seu relato, é possível perceber a conscientização acerca dos desafios enfrentados por ela e como esses podem ser vistos, por outros docentes, como empecilho e motivador para não usar as TIC:

[...] é necessário apontar que ainda que as tecnologias de informação facilitem alguns meios de trabalho, a sua utilização também demanda tempo considerável por parte do professor. Claro, um tempo bem aproveitado, pois que se trata de aprendizado para o próprio professor. Entretanto, ele pode se transformar em frustração diante da possibilidade de não funcionamento de alguns dos aspectos da tecnologia envolvida (MORGANA 2018, [n. p.], grifos nossos).

A voz narrativa do texto de Mariele aponta para os pontos positivos do uso das TIC em sala de aula, mas também ressalta as dificuldades em colocar em prática o planejado:

Por fim, os aprendizados após o uso das tecnologias é que elas auxiliam na elaboração de uma aula mais atrativa e dinâmica, assim como, facilitam o compartilhamento de informações e conhecimento, porém, destacamos que a utilização desses recursos deve ser pensada a partir da realidade singular de cada docente, tendo em vista que a utilização desses recursos demanda tempo extrassala de aula, e, infelizmente, essa não é a realidade da maioria dos professores(as) brasileiros de escola pública (MARIELE, 2018, [n. p.], grifos nossos).

Ao utilizar a conjunção adversativa, porém e o verbo destacar, na primeira pessoa do plural, o narrador expõe a perspectiva dele e de Mariele acerca dos pontos negativos 
do uso das TIC (demanda de tempo extrassala). Apesar de apontar para os desafios enfrentados, ela justifica sua opinião e apresenta uma solução (pensar a realidade singular de cada professor). Nesse excerto é possível, ainda, identificar a voz implicada de professora de escola pública de Mariele, pois fala da realidade vivenciada por ela e seus colegas docentes. Esse ponto de vista auxilia na compreensão da situação da educação pública e dá um embasamento de como posso é possível o docente prepararse para adentrar tal cenário.

\section{Reflexões e considerações finais}

Quando estudamos sobre as TIC, principalmente sobre a sua implementação no ambiente escolar, parece-nos muito fácil colocá-las em prática e dizer que o professor precisa usá-las em suas aulas. Porém, somente quando somos desafiados a efetivar tais ideias percebemos a complexidade e o fato de não ser tão simples quanto imaginamos. Essa perspectiva me foi possível ao refletir sobre a construção de um plano de aula que abrangesse TIC, a prática docente de Morgana e Mariele e seus respectivos relatórios.

Durante todo o processo, pude perceber um dos pontos mais significativos deste exercício: o interesse e a vontade das doutorandas em aceitar minhas ideias, buscando aprender sobre as ferramentas indicadas. Isso é extremamente importante, pois se o professor não deseja mudar sua prática pedagógica, achando as TIC como algo desnecessário, é praticamente impossível que ele as inclua em suas aulas. Em todos os momentos da preparação das aulas, Morgana e Mariele comentavam sobre o quão amplo e diversificado é o "mundo" das TIC. Elas também perceberam como é importante saber sobre os recursos tecnológicos, assim como se informar e fazer cursos de capacitação relacionado ao uso desses em sala de aula.

Quando os professores, mais especificamente os de Literatura, no que concerne o foco deste trabalho, compreenderem que os alunos e suas formas de adquirirem conteúdos mudam com o passar dos anos, e que, para atingir esse público, eles precisam se atualizar, poderão, então, modificar suas práticas pedagógicas. O acesso à internet e, consequentemente, a informações diversas, possibilita aos discentes encontrarem 0 conteúdo literário, às vezes, de maneira mais interessante do que a forma abordada pelo professor. Aproveitar isso, por meio de pesquisa ou perguntando aos próprios alunos, pode ser uma maneira de o docente construir um plano de aula entrelaçando temática curricular e TIC. Cursos de capacitação/formação sobre TIC também podem ser um meio de o docente aprender a usar em sala de aula as ferramentas disponíveis ${ }^{11}$.

Para um ensino-aprendizado de Literatura mais próximo dos alunos nativos digitais, há a necessidade de os professores se apropriarem das novas tecnologias. Ao trazer imagens, efeitos sonoros para contação da história, versões e adaptações do texto literário, como Morgana e Mariele fizeram, ou introduzir o livro digital e a leitura de textos encontrados na rede, por exemplo, o professor auxilia o aluno a entender e utilizar a

11 Em Santa Maria, o Núcleo de Tecnologia Educacional (NTE UFSM) oferece inúmeros cursos de capacitações, bem como especializações, que proporcionam o aprendizado de TIC aplicadas à educação. Ex.: Oficina Games na educação; mapas conceituais na produção de material didático; Ferramentas web para apresentação de conteúdo; Autoria colaborativa em rede; Material didático hipermídia no AVEA Moodle para docentes; etc. 
internet como fonte de pesquisa e auxiliadora na construção do aprendizado. O estudante passa a ir além do uso somente da web como acesso a redes sociais, ampliando assim o seu acesso à informação. O aluno realiza a leitura digital, deparando-se com textos com links e hipertextos, o que rompe com a linearidade e amplia as possibilidades de intervenção do leitor, permitindo conexões e acesso a outras fontes de conhecimento, construindo práticas efetivamente interdisciplinares. Dessa forma, aquele ensino equivocado da Literatura Infantil, que abrange apenas a leitura dos contos e atividade de pinturas de desenhos relativos a ele, ou apenas ver uma adaptação fílmica sem discussão (que pouco contribui para a formação de leitores de literatura, tampouco de leitores críticos) amplia-se.

Por meio da inclusão do aluno em ambientes com conteúdos relevantes e de uma abordagem diferenciada, será possível que ele perceba como eram determinadas épocas, costumes e histórias. Poderá refletir a respeito delas, entendendo a nossa sociedade e revelando que, por meio dos textos literários, é possível conhecer a nossa História, e, a partir disso, ampliar nossas perspectivas e opiniões. A possibilidade de esse aluno tornarse mais reflexivo, crítico e atento ao modo como nossa sociedade se constituiu e se constitui será então maior. Entretanto, o professor pode mediar esse processo, mostrando ao aluno-leitor a necessidade de estar atento para não perder o foco e selecionar informações relevantes para o que está sendo estudado. Para isso, "[...] é preciso construir uma ponte resistente entre o mundo que se vive e a sala de aula, estando atento ao cenário cultural deste grupo de alunos" (PACHLER, 2014 apud BRATKOWSKI; BAGGIO, 2014, p. 4).

O professor pode refletir sobre quais tecnologias poderá utilizar em suas aulas, considerando os seguintes pontos: elas lhe auxiliarão a atingir seu objetivo, a finalidade pretendida?; elas despertarão nos alunos o interesse pelo conteúdo, contribuindo para o aprendizado?; elas contribuirão para tornar a obras literárias do currículo mais interessantes, despertando o gosto pela literatura e pela leitura?

Conforme observado durante o desenvolvimento deste trabalho, as ferramentas disponíveis na web realmente auxiliam no aprendizado do estudante de literatura. Os recursos escolhidos e usados por Morgana e Mariele, como o Prezi e os vídeos, por exemplo, estimularam os estudantes a participarem das aulas de maneira ativa, questionando e contribuindo para o debate das temáticas abordadas. Os estudantes buscaram trazer, em seus seminários, mais informações sobre os contos, meios de apresentá-los de formas diferentes, a utilizarem os recursos para elaborar o trabalho (Google Drive, Power Point etc.) e o plano de aula, a realizarem pesquisas na internet ${ }^{12}$, bem como abrir e usar o ambiente da disciplina no Moodle da UFSM, tanto para acessar os tutoriais disponíveis como para postar os materiais produzidos por eles e as versões e adaptações dos contos por eles encontradas.

Todavia, esse ânimo e intenção das doutorandas em sempre usar as TIC foram abalados no decorrer da Docência orientada. Conforme indicado na seção anterior, os inúmeros imprevistos e problemas com alguns recursos educacionais e equipamentos tecnológicos deixaram Morgana e Mariele frustradas. Segundo elas, houve a dedicação

12 Uma das aulas, após o término dos seminários de Morgana e Mariele, foi dedicada ao atendimento dos alunos, a fim de orientá-los acerca da elaboração do seminário. Nessa aula, auxiliamo-nos também sobre como montar uma apresentação de conteúdo, realizar pesquisas na internet, usar as TIC usadas pelas professoras e elaborar um plano de aula. 
de muito tempo para: fazerem uma boa apresentação, tanto no Power Point como no Prezi; baixarem os vídeos, imagens e sons necessários; entenderem o funcionamento de uma ferramenta. $E$, às vezes, esses recursos não funcionaram como deveriam ou não atenderam ao desejado, como o Powtoon, por exemplo. Além disso, no momento de usar tais recursos, algo acontecia com os equipamentos ou arquivos, prejudicando o material e a utilização deles. Esses imprevistos resultavam em um pensamento negativo por parte das acadêmicas, o que permitia-lhes pensar que esses podiam ser motivos pelos quais vários professores relutam em usar as TIC em sala de aula, principalmente nas escolas em que os equipamentos estão sucateados.

A partir disso, Morgana, Mariele e eu refletimos sobre como a elaboração de aulas envolvendo uso de TIC, quando se está iniciando o processo de aprendizado de como usá-las e quais usar em cada momento, exige tempo, empenho e força de vontade para não desistir. Mariele, professora do Ensino Fundamental, comentou, em uma das reuniões para elaboração das aulas, que, muitas vezes, a escola não tem infraestrutura necessária, como computador, projetor, caixas de som, TV com cabo VGA ou HDMI, inviabilizando várias das ferramentas mais simples, como projetar algo ou levar um vídeo baixado da internet. Quando têm esses equipamentos, não é feita a manutenção regular ou o incentivo ao uso ou não propicia a capacitação dos professores, mantendo distante a ideia de ensino mediado pelas tecnologias educacionais.

Apesar dos desafios e contratempos enfrentados, Morgana e Mariele não quiseram desistir do nosso projeto, pois têm consciência de como os recursos tecnológicos, hoje em dia, são ótimos aliados no ensino. O professor não é mais o "detentor do conhecimento", enquanto os alunos são passivos no processo de aprendizado, mas sim um mediador, que auxilia os alunos na construção de conhecimento.

As complicações e desânimo não prejudicaram o entendimento das doutorandas sobre as TIC serem importantes para a construção do ensino-aprendizado dos nativos digitais, pois fazem parte do cotidiano deles. É muito válido aproximar a escola das vivências e práticas dos estudantes e também daqueles que não têm a oportunidade de acessar a internet e os mais variados recursos em casa, por causa de sua condição social, preparando-os para o que, provavelmente, encontrarão no mercado de trabalho e em outras instituições de ensino. Mesmo que a escola não tenha internet ou laboratório de informática, ferramentas off-line e programas para baixar vídeos da internet podem ser utilizados.

Ao analisar todas essas questões, percebo que um ponto importante para a implantação das TIC em sala de aula é a manutenção e/ou ampliação da carga horária da hora-atividade de cada professor. Trata-se de um período essencial que possibilita ao docente mais tempo para preparar aulas que envolvam o uso das tecnologias, importante diante da demanda de tempo e da dedicação na elaboração do uso dessas práticas, no entrelaçamento entre conteúdo e ferramenta tecnológica, bem como no manuseio e configuração do recurso, de forma a atender às necessidades dos alunos.

Essa atividade, idealizada pela disciplina de Sala de aula e TIC, além de oportunizar o exercício docente utilizando-se das TIC para o ensino-aprendizado, permitiu a reflexão sobre essa prática e como nós docentes podemos traçar soluções para as dificuldades enfrentadas ao empregar os recursos tecnológicos no ensino. Além disso, reforça a ideia da importância de nos mantermos em constante formação e aprendizado sobre as ferramentas educacionais. 
Por fim, todas as considerações aqui tomadas, a partir do desenvolvimento da reflexão acerca do relatório e da prática, levam-nos a perceber que as TIC não são a solução dos problemas educacionais, mas são ferramentas para melhorar os processos de aprendizagem. O seu uso facilita o aprendizado e permite a circulação e armazenamento de informações, multiplicando possibilidades da utilização.

\section{Referências}

ALMEIDA, M. E. B. de. Tecnologia na escola; criação de redes de conhecimento. In: MORAN, J. M. (org.). Integração das tecnologias na educação. Secretaria de Educação a Distância. Brasília: Ministério da Educação, SEED, 2005. p. 70-73. Disponível em: http://portal.mec.gov.br/seed/arquivos/pdf/2sf.pdf. Acesso em: 25 fev. 2018.

BAL, M. Narratology: introdution to the theory of narrative. Trad. Chistine Van Boheemen. 4 ed. Toronto: Universityof Toronto Press, 2017.

BARREIRO, I. M. de F.; GEBRAN, R. A. Prática de ensino e estágio supervisionado na formação de professores. São Paulo: Avercamp, 2006.

BELLEI, S. L. P. Hipertexto e literatura. Porto Alegre: EdiPUCRS, 2012.

BRATKOWSKI, B. R.; BAGGIO, J. E. Literatura e TIC: a formação do leitor na era digital. In: Manancial: repositório digital da UFSM. Santa Maria: UFSM, 2014. Disponível em: http://repositorio.ufsm.br/handle/1/3117. Acesso em: 03 out. 2017.

COPPOLA, N. C.; RAMOS, M. O uso do computador e da internet como ferramentas pedagógicas. Secretaria da Educação do Paraná, 2009. Disponível em: http://www.diaadiaeducacao.pr.gov.br/portals/pde/arquivos/2551-8.pdf. Acesso em: 03 mar. 2018.

MORGANA. Relatório de docência orientada II: primeiro semestre letivo de 2018. Relatório final da disciplina Docência orientada PPGLetras/UFSM, Santa Maria, 2018.

MARIELE. Relatório de docência orientada II: primeiro semestre letivo de 2018. Relatório final da disciplina Docência orientada PPGLetras/UFSM, Santa Maria, 2018.

NÓVOA, A. (org.). Os professores e a sua formação. 2 ed. Lisboa: Dom Quixote, 1995.

RAMAL, A. C. Educação na Cibercultura: hipertextualidade, leitura, escrita e aprendizagem. Porto Alegre: Artmed, 2002.

REIS, C.; LOPES, A. C. M. Dicionário de narratologia. Coimbra, Almedina, 1996.

REZENDE, N. L. de. O ensino de literatura e a leitura literária. In: DALVI, M. A. et al. (org.). Leitura de literatura na escola. São Paulo: Parábola, 2013. p. 99-112. 
VAILLANT, D.; MARCELO, C. Ensinando a ensinar: as quatro etapas de uma aprendizagem. Curitiba: UTFPR, 2012.

Recebido em dia 25 de fevereiro de 2019. Aprovado em dia 26 de março de 2019. 